\title{
Complementary feeding practices: determinants of dietary diversity and meal frequency among children aged 6-23 months in Southern Benin
}

\author{
Irene Medeme Mitchodigni ${ }^{1}$ - Waliou Amoussa Hounkpatin ${ }^{1}$ - Gervais Ntandou-Bouzitou ${ }^{2}$. \\ Hermane Avohou $^{1}$ - Celine Termote ${ }^{3}$ - Gina Kennedy ${ }^{3}$ • D. Joseph Hounhouigan ${ }^{1}$
}

Received: 18 January 2017 / Accepted: 22 August 2017 / Published online: 21 September 2017

(C) The Author(s) 2017. This article is an open access publication

\begin{abstract}
Poor complementary feeding practices have detrimental effects on child growth, development and survival. This cross-sectional study in rural areas of southern Benin examined some determinants of complementary feeding practices using socioeconomic and dietary data collected among 1225 primary caregivers. Determinants of complementary feeding practices in the study areas are multidimensional and include many interacting factors such as socio-economic aspects, farming practices, household demographics, cultural practices and geography. Child age, diversity of food groups produced, income allocated to feeding, commune of residence, ethnicity, caregivers' occupation, marital status and household size were identified as the main factors affecting complementary feeding practices. Food group diversification in farm-systems and overall social behavior and support as well as women's empowerment are necessary to improve children's diets. Reducing women's workload through improved working conditions appears crucial to decrease time burdens and allow more time for child care. Multisectoral interventions should be embraced to improve complementary feeding practices in Benin.
\end{abstract}

Electronic supplementary material The online version of this article (https://doi.org/10.1007/s12571-017-0722-y) contains supplementary material, which is available to authorized users.

Irene Medeme Mitchodigni irenemedeme@gmail.com

1 Faculty of Agronomic Sciences, University of Abomey-Calavi, 03 BP 2819 Jericho, Cotonou, Benin

2 Bioversity International, Bioversity International, Cotonou, Benin

3 Bioversity International, Nairobi, Kenya
Keywords Complementary feeding practices · Dietary diversity $\cdot$ Meal frequency $\cdot$ Diversity of food group produced . Gender $\cdot$ Benin

\section{Introduction}

Complementary feeding refers to children aged 6-23 months, a challenging period until the child is able to eat like the rest of the family. It is the process of introducing complementary foods, which are any non-breastmilk foods or nutritive liquids that are given to young children from 6 months to above (WHO, 2008). It is a transition from exclusive breastfeeding to family foods and a very vulnerable period in which malnutrition starts in many infants, contributing significantly to the high prevalence of malnutrition in children under five years of age world-wide. Achieving appropriate complementary feeding of young children is a crucial milestone in efforts to enhance survival and promote healthier growth and development of children (Menon, 2012). Inappropriate complementary feeding practices during the first two years of childhood drastically increase morbidity, mortality and risks of chronic diseases. Poor complementary feeding practices have detrimental effects on overall growth and development of children (Black et al., 2013; Khanal, Sauer, \& Zhao, 2013). Worldwide, about one-third of the mortality of children under five years is caused by malnutrition related to inadequate complementary feeding (WHO, 2003).

Complementary feeding practices are still poor in most developing countries and are even worsening in some of them (Lutter et al., 2011). For instance, national assessments available in West African countries reported that the prevalence of a minimum acceptable diet ranged from $11.0 \%$ in Nigeria (2003) to $29.9 \%$ in Ghana (2007) (Issaka, Agho, Burns, Andrew, \& Dibley, 2014; Ogbo, Page, Idoko, Fernanda, \& Agho, 2015). 
In Benin, $15 \%$ of children met the minimum acceptable diet (WHO, 2010). This persistent prevalence of inadequate complementary feeding requires more intensive and efficient efforts from different organizations to improve the situation (Lutter et al., 2011), requiring a better understanding of the drivers of inappropriate complementary feeding as well as better identification of vulnerable groups (Lutter et al., 2011; Issaka et al., 2015c). Until now, very few studies have investigated these drivers in order to understand the complex processes underlying inappropriate feeding practices at individual, household and community levels (Menon, 2012; Chapagain, 2013; Issaka et al., 2015b; Ogbo et al., 2015). Moreover, major explanatory factors highlighted by these studies include mainly socioeconomic factors such as cultural beliefs and habits, household poverty, maternal literacy and ignorance of appropriate practices (Menon, 2012; Chapagain, 2013; Issaka et al., 2014; Ogbo et al., 2015). Maternal education level, for example, could influence complementary feeding practices with potentially beneficial effects on child nutritional status. Indeed, Agueh, Makoutode, Diallo, Soton, and Ouendo (1999) found that mothers' instruction level had a tendency to be positively and significantly associated with child wasting (weight for height) z-scores.

Recent studies in Benin showed the important role of crop diversity in dietary habits of rural people and the complex relationships between socioeconomic characteristics of households and their access and use of these resources (Segnon \& Achigan-Dako, 2014; Bellon, Ntandou-Bouzitou, \& Caracciolo, 2016). However, the influence of such socioeconomic factors on complementary feeding practices have rarely been investigated in Benin.

Therefore, the present study aims to assess the adequacy of complementary feeding practices of infants aged 6-23 months in rural areas in Southern Benin and identify key factors that influence them and key socio-economic characteristics of vulnerable groups where practices are inadequate. We hypothesize that the adequacy of complementary feeding practices is determined by the combined effects of socioeconomic and cultural factors, household and caregiver characteristics, in association with factors related to agricultural and food diversity, availability and accessibility.

\section{Methods}

\subsection{Study design}

A cross-sectional survey was performed in two communes of Mono Department, Southern Benin. Data were collected over a three month period, from October to December 2013, a transition period between the short rainy season and the long dry season. This period corresponded to moderate food availability. Harvesting is the main agricultural activity undertaken.

\subsection{Research setting}

The study was carried out in two rural communes Bopa (latitude: 6.702; longitude: 1.949) and Houeyogbe (latitude: 6.532; longitude: 1.870), in Mono Department, Southern Benin. Mono department was chosen because of the high level of malnutrition, which contrasts with the high agricultural biodiversity in this area. Bopa and Houeyogbe were selected due to their high food insecurity index $(40.5 \%$ and $34.1 \%$, respectively). The study sites are located in slightly contrasting environmental conditions and socioeconomic contexts. Bopa is landlocked and less densely populated (264 inhabitants $/ \mathrm{km}^{2}$ ) than Houeyogbe (315 inhabitants $/ \mathrm{km}^{2}$ ) (Sarl, 2010; Benin Consulting, 2011; INSAE-Benin, 2013).

The soil in Bopa is dominated by vertisol while land in Houeyogbe is dominated by ferralitic and patches of hydromorphic soils. Vertisols are more fertile than ferralitic soils. The natural vegetation is more degraded by anthropogenic pressure in Houeyogbe than Bopa. Thus, Bopa has a more diversified natural vegetation including tree species such as baobab (Adansonia digitata) and kapok tree (Ceiba pentandra). There are reforested perimeters consisting mainly of teak (Tectona grandis), acacia (Acacia auriculiformis), iroko (Milicia excelsa), samba (Triplochyton scleroxylon), Elaeis sp. and fruit trees. The herbaceous vegetation consists of grasses, marshy grasslands and a mangrove along the "Aheme" lake.

Bopa is also more farming-oriented ( $82 \%$ of households) compared to Houeyogbe (47\% of households). The main crops produced in the study area include: maize (Zea mays), cassava (Manihot esculenta), sweetpotato (Ipomoea batatas) - cereals, roots and tubers group-, cowpea (Vigna unguiculata), groundnut (Arachis hypogaea), palm oil (Elaeis guineensis)- legume and nuts group-, Jew's mallow (Corchorus olitorius), amaranth (Amaranthus cruentus), tomato (Solanum lycopersicon), okra (Abelmoschus esculentus), pawpaw (Carica papaya), banana (Musa spp.) -fruits and vegetables. The main animal species reared are chicken (Gallus gallus domesticus), duck (Cairina moschata), goat (Capra aegagrus) and fish (Tilapia guineensis) -flesh foods group. Gardening is more widely practiced in Bopa than Houeyogbe. In Bopa with the proximity of the "Aheme" lake, many households also engage in fishing activities. Women are involved in all agricultural activities, especially in crop production, livestock keeping and home gardens. Harvesting and post-harvest activities - drying, storage, preservation, processing and marketing of agricultural products are time consuming and are predominately implemented by women. Regarding living standards, the poverty threshold is lower in Bopa [291 XOF (=0.50 USD) per capita (XOF: means the code of FCFA which is the currency used in the UEMOA area including Benin.)], with a poverty rate of $33 \%$ ) compared to Houeyogbe (328 XOF (=0.56 USD) per capita with a poverty rate of 43\%) (Schreiner, 2012). 


\subsection{Respondents and sampling}

The study focused on children aged 6 to 23 months and their mothers or primary caregivers.

The sample size was calculated using a classic formula for sample size calculation:

$$
\mathrm{N}=\left[\mathrm{Z}^{2} * \mathrm{p}(1-\mathrm{p}) / \mathrm{m}^{2}\right] * \mathrm{DE} * 1 /(1-\lambda)(\text { Magnani, 1997), }
$$

where $\mathrm{N}$ refers to the required sample size in each commune: Bopa and Houeyogbe; $\mathrm{Z}$ is the $\mathrm{z}$-value corresponding to the level of confidence of $95 \%$, thus equals 1.96 ; $p$ is the estimated prevalence of childhood stunting in Mono province in 2006 at $44.7 \%$ (INSAE-Benin, 2006); $\mathrm{m}$ is the margin of error at $5 \%$ (standard value of 0.05 ); DE is the design effect fixed at $2.8(1.4 \times 2)-$ due to cluster sampling with Bopa and Houeyogbe representing two different clusters; $\lambda$ is the refusal rate (household non-response) fixed at $10 \%$.

An initial sample size of 1182 children was obtained and further extended to 1190 .

A multistage sampling method was used in selecting participant villages and subjects. Briefly, the estimated sample size (1190) was allocated to the two communes proportionally to the population size of children from 0 to 2 years old, $47 \%$ for Bopa $(n=560)$ and $53 \%$ for Houeyogbe $(n=630)$. A total of 17 villages (8 and 9 in Bopa and Houeyogbe, respectively) were randomly selected from a list of villages in each commune with infant populations equal or above 80 subjects. In each selected village, all households with at least one child between 6 and 23 months old were systematically selected to be enrolled in the study upon satisfaction of the following inclusion criteria: children must be 6 to 23 months old, complementarily fed, not suffer severe illness or malnutrition; caregivers and their children must have lived in the village for the past 2 years and were not planning to leave in the next year. Twenty one children did not meet inclusion criteria. Finally, 1263 households were selected of which 1225 households completed all questionnaires. Within each household, the household head and the mother or child caregiver were interviewed. Where more than one child aged between 6 and 23 months old was found in the same household, the interviews focused on the youngest child.

\subsection{Data collection and processing}

Data were collected in local languages by well trained and experienced interviewers with bachelor's degrees as minimum grade. Structured questionnaires were used to collect demographic and socioeconomic household characteristics, including food security status measured by the Household Food Insecurity Access Scale, (Coates, Swindale, \& Bilinsky, 2007). Agricultural production and availability of the previous year as well as utilization of local biodiversity were also integrated into the questionnaire.

Additionally, gender aspects, households' sanitation, child feeding and care practice data were collected. Two nonconsecutive 24-h recalls were used to assess child dietary intakes. Primary caregivers recalled the meals, drinks and snacks the child had consumed the previous day in a 5 stepmethod described in Gibson and Ferguson (2008). Intake data were entered and processed with Lucille software developed by Gent University, Belgium. The other data were entered and processed with Microsoft Access. All filled questionnaires were cross-checked by field supervisors as well as the principal investigator (first author). The data were entered twice by two different individuals who were blind to the other's entries. Subsequently, databases were screened for discrepancies and cleaned.

\subsection{Explanatory variables}

Five groups of potential explanatory variables were identified from the literature (Fein, Labiner-Wolfe, Scanlon, \& Grummer-Strwan, 2008; Upul, Sanjeeva, Hiranya, Indika, \& Michael, 2012; Khanal et al., 2013; Melkam, Molla, Zelalem, \& Azeb, 2013; Brown et al., 2014; Issaka et al., 2015a, b).

The first group of potential variables is related to socioeconomic characteristics of households. It included 8 variables namely: (1) the commune of residence (Bopa or Houeyogbe), (2) the sex of the household head (male or female), (3) primary and other income sources of the household, (4) the sociolinguistic group of household head (native Saxwe or others), (5) the marital status of the mother (alone - single, divorced, widowed, married but living alone - or not alone married and living with husband), (6) the household size, (7) the number of children under 5 years (categorized on an ordinal scale, normal is $\leq 2$ and high is $>2$ ) and (8) the household wealth index. The last is a composite variable of a household's cumulative living standards. It was developed using a series of nineteen assets, proxy variables used in the DHS survey and wealth index construction for rural areas in Benin (Rutstein \& Kiersten, 2004; Vyas \& Kumaranayake, 2006): housing characteristics (house construction materials, energy source for lighting and meal cooking); durable asset ownership (means of transportation, media and communication assets); and access to utilities and infrastructure (health center access, transportation means used to access markets or health centers, the availability and quality of household sanitary facilities and practices such as water sources, state of toilets, waste management and overall hygiene habits). Each household was assigned a score for each asset variable using principal components analysis. The scores were then summed for each household to derive the corresponding wealth index. Further, based on the quintiles of the wealth index, households were classified into five socioeconomic status categories, from the 
poorest to the richest category (Filmer \& Pritchett, 2001; Vyas \& Kumaranayake, 2006).

The second group of variables refers to the households' food insecurity, food availability and accessibility. It includes: (1) the share of the household income allocated to food (categorized on an ordinal scale; $\leq 50 \%$ is normal, $50-75 \%$ is moderately high, $>75 \%$ is high); if a high percentage is allocated to food, people are really poor (INSAE-Benin, 2014); (2) the food availability (related to the duration of food shortage experienced by the household (Bilinsky \& Swindale, 2010) and coded on an ordinal scale as follow: very low- 5 to 11 months of shortage, low - 3 to 4 months of shortage, medium - 2 months of shortage and high -0 to 1 month of shortage and (3) the household food insecurity which is an ordinal scale variable determined with the Household Food Insecurity Access Scale (HFIAS) (Coates et al., 2007; Bilinsky \& Swindale, 2010). Households were categorized into four levels of household food insecurity (access): food secure, mildly, moderately and severely food insecure.

The third group of explanatory variables is related to production diversity and assets that might affect this diversity. It includes: (1) production diversity defined as the number of different food groups produced over the past year in analogy with the WHO classification for infant and young child dietary diversity (WHO, 2008; Berti, 2015); (minimum $=0$ and maximum $=7$ food groups); (2) the ownership of a home garden, which indicates the availability of vegetables at the household level.

The fourth group of potential explanatory variables refers to social support. It includes only one binary variable which refers to any support received by the household in terms of training, awareness, counseling, financial or material support related to child care practices. This is a categorical variable: yes if the household received any type of support or no, if none of the above cited types of support were received.

The fifth group of variables includes child, maternal and caregiver characteristics that might influence the feeding practices: (1) age of the child which may affect the choice of adequate complementary foods, (2) age of the mother as proxy of maturity which may reflect her experience, (3) education level of the mother which may affect her knowledge (coded as no schooling or any form of formal schooling), (4) mother's occupation which may reflect her availability to take care of the child (coded as no occupation and worker); and (5) the maternal sociolinguistic group ("Saxwe" or others) which may reflect beliefs and dietary habits.

\subsection{Outcome variables}

Among the set of infant and young child feeding (IYCF) practices indicators defined by WHO (2008), two have been explored in this work as outcome variables: (1) minimum dietary diversity (MDD) and (2) the minimum meal frequency (MMF). Child breastfeeding status was taken into account.

- The MDD is defined as the proportion of children aged 623 months who consumed foods from at least four food groups out of the seven referenced food groups within a 24-h time period. The seven food groups are: (1) grains, roots and tubers, (2) legumes and nuts, (3) dairy products, (4) flesh foods (meat, fish, poultry and liver/organ meats), (5) eggs, (6) vitamin A-rich fruits and vegetables and (7) other fruits and vegetables (WHO, 2008).

- The MMF is the proportion of breastfed and nonbreastfed children aged 6-23 months who received solid, semi-solid or soft foods (but also including milk feeds for non-breastfed children), the minimum number of times or more. The minimum number of times was set to two and three meals for breastfed infants aged 6-8 months and 923 months, respectively; and four meals for non-breastfed children aged 6-23 months (WHO, 2008).

- The Minimum acceptable diet (MAD) is defined as the proportion of children 6-23 months of age who had both minimum meal frequency and dietary diversity (in both breastfed and non-breastfed children) during the previous day (WHO, 2008; UNICEF, 2011).

The age bracket (6-23 months) was further disaggregated into the following age groups: $6-11$ months, $12-17$ months and 18-23 months (WHO, 2008).

WHO infant and young child feeding (IYCF) indicators focusing primarily on breastfeeding were outside the scope of this study on complementary feeding practices. Also, the paper did not focus on the minimum acceptable diet (MAD), as this is a composite indicator of MDD and MMF, which reflects both quality and quantity of diet. Indicators on 'consumption of iron-rich or iron-fortified foods' will be discussed in a subsequent paper dealing with quantitative dietary intake data and nutrient adequacy of diets.

\subsection{Statistical analysis}

Descriptive statistics and Wilcoxon rank test and Chi-square test were used to describe and compare the two study areas. Simple logistic regressions were computed using MDD and MMF as dependent variables to preselect candidate explanatory variables. Multiple logistic mixed regressions were further used to test significance of the effects of the preselected explanatory variables. Fixed terms included the preselected variables and all two-order interactions. Villages were included as a clustering variable. The final model was constructed using a backward elimination approach, where non-significant terms were excluded, based on the likelihood ratio test at a significance level of 0.05 . Plots of predicted probabilities of 
meeting MDD or MMF were then used to examine significant relationships among variables.

Statistical analyses were performed in " $R$ " software (Team, 2015). For screening of variables with simple logistic regression, we used the function 'glm' of the package 'stats'. Logistic mixed regression models were performed with the function 'glmer' of the package 'Ime4'(Crawley, 2013).

\section{Results}

\subsection{Characteristics of the sample}

The socio-economic and demographic profiles of children, primary caregivers and households are presented in Table 1. Among the 1225 children enrolled in the study, over one-third was between 6 and 11 months old. The majority of primary caregivers (98\%) were the mothers. They were generally young (average $28 \pm 3.7$ years) with more than half of them under thirty. Most of the mothers did not attend formal school and were illiterate, with the highest proportion observed in Bopa commune. Most mothers (97\%) pursued income generating activities such as agriculture, post-harvest handling, food processing and small trade. The majority of households (94\%) were male-headed. Mean household size was significantly higher in Bopa $(5.5 \pm 2.0)$ than Houeyogbe $(5.1 \pm 1.8)$. The dominant ethnic group is "Saxwe" (77\% of interviewees). Only $10 \%$ of households reached a production diversity of 4 or more food groups, with a higher proportion observed in Bopa. Mean diversity of food groups produced (DFGP) score was also significantly higher in Bopa $(2.3 \pm 1.2)$ than Houeyogbe commune $(1.3 \pm 1.1$ : Table 1). More than $80 \%$ of households were food insecure with a significantly higher rate in Houeyogbe commune. On the contrary, the proportion of the poorest households was significantly higher in Bора than Houeyogbe ( $40 \%$ vs $36 \% ; p<0.001)$.

\subsection{Types of foods given to child by age}

Table 2 presents the proportion of surveyed children consuming the different food groups and the derived dietary diversity scores (DDS). Cereals, roots and tubers were the most widespread food groups used to feed children. Half of the children were fed with vitamin A rich foods but only $2 \%$ of the children consumed eggs. Except for eggs and dairy products, the group of children aged between 18 and 23 months had the highest consumption rates for all food groups.

\subsection{Complementary feeding indicators}

Figure 1 shows the proportion of children meeting the selected WHO complementary feeding indicators in each commune. The prevalence of minimum dietary diversity (MDD) among the children aged 6-11 months in Bopa and Houeyogbe were $49 \%$ and $39 \%$, respectively. The corresponding rates among children aged $12-17$ months were $74 \%$ vs $62 \%$ and were $71 \%$ vs $75 \%$ for $18-23$ months children. The rates of MDD among children of Houeyogbe increased significantly with the age of children. However, the prevalence of minimum meal frequency (MMF) within age group in Houeyogbe were significantly different.

\subsection{Factors associated with complementary feeding practices}

Four main factors were found significantly associated with minimum dietary diversity, either positively or negatively: (1) child's age, (2) production diversity, (3) combined effect of share of income allocated to feeding and commune of residence and (4) the combined effect of ethnicity and commune (Table 3). While the probability of meeting minimum dietary diversity increased with child's age and with increased diversity of food groups produced (DFGP) (number of food groups grown) $(p<0.05)$, it decreased substantially when income allocated to food purchase increased in Houeyogbe commune $(p<0.05)$. However, there was no substantial effect of income allocated to food on the probability of minimum dietary diversity in Bopa $(p<0.05)$. The chance of meeting MDD decreased substantially for "Saxwe" people residing in Houeyogbe while it increased among minority groups $(p<0.05)$.

The probability of meeting minimum meal frequency was significantly affected by three factors namely (1) ethnicity, (2) caregiver's occupation and (3) the combined effect of marital status and size of household (Table 4). Children from minority ethnic groups (other than the native "Saxwe" people) were more likely to meet MMF, while those of large household size and those whose mother/primary caregivers are involved in income-generating activities, were less likely to meet MMF $(p<0.05)$. Increase in household size had a detrimental effect on children's probability of minimum meal frequency among single mothers $(p<0.05)$.

\section{Discussion}

To our knowledge, this is one of the first publications in Benin that explores determinants of complementary feeding practices using selected WHO recommendations (WHO, 2008). Factors positively or negatively associated with compliance to recommended complementary feeding practices were children's age, caregivers' occupation and marital status, ethnicity of household head, household size, production diversity, share of household income allocated to feeding and commune of residence. Interactions noticed between some of these factors 
Table 1 Households and individuals characteristics in the study communes (Bopa and Houeyogbe $),(n=1225)$

\begin{tabular}{|c|c|c|c|c|c|c|c|}
\hline \multirow[t]{3}{*}{ Characteristics } & \multirow{2}{*}{\multicolumn{2}{|c|}{ All }} & \multicolumn{4}{|c|}{ Communes } & \multirow[t]{3}{*}{$p$-value } \\
\hline & & & \multicolumn{2}{|c|}{ Bopa } & \multicolumn{2}{|c|}{ Houeyogbe } & \\
\hline & $\mathrm{n}$ & $\%$ & $\mathrm{n}$ & $\%$ & $\mathrm{n}$ & $\%$ & \\
\hline \multicolumn{8}{|l|}{ Characteristics of children } \\
\hline \multicolumn{8}{|l|}{ Age (months) } \\
\hline $6-11$ & 460 & 37.6 & 222 & 39.9 & 238 & 35.6 & \multirow[t]{3}{*}{0.188} \\
\hline $12-17$ & 402 & 32.8 & 183 & 32.9 & 219 & 32.8 & \\
\hline $18-23$ & 363 & 29.6 & 152 & 27.3 & 211 & 31.6 & \\
\hline \multicolumn{7}{|l|}{ Gender } & \multirow[t]{3}{*}{0.440} \\
\hline Male & 633 & 51.7 & 286 & 51.3 & 347 & 51.9 & \\
\hline Female & 592 & 48.3 & 271 & 48.7 & 321 & 48.1 & \\
\hline \multicolumn{8}{|l|}{ Characteristics of caregivers } \\
\hline \multicolumn{8}{|l|}{ Caregivers } \\
\hline Primary caregivers & 1202 & 98.1 & 546 & 98 & 656 & 98.2 & 0.624 \\
\hline others & 23 & 1.9 & 11 & 2 & 12 & 1.8 & \\
\hline Caregivers'age (year), (mean $\pm \mathrm{SD}$ ) & \multicolumn{2}{|c|}{$28.35 \pm 3.66$} & \multicolumn{2}{|c|}{$28.82 \pm 6.42$} & \multicolumn{2}{|c|}{$27.97 \pm 6.83$} & 0.027 \\
\hline \multicolumn{7}{|l|}{ Age (years) } & \multirow[t]{4}{*}{0.012} \\
\hline$<20$ years old & 60 & 4.9 & 20 & 3.6 & 40 & 6 & \\
\hline 20-29 years old & 638 & 52.1 & 275 & 49.4 & 363 & 54.3 & \\
\hline$\geq 30$ years old & 527 & 43 & 262 & 47 & 265 & 39.7 & \\
\hline \multicolumn{7}{|l|}{ Education } & \multirow[t]{3}{*}{$<0.001$} \\
\hline Formal schooling & 400 & 32.7 & 109 & 19.6 & 291 & 43.6 & \\
\hline No schooling & 825 & 67.3 & 448 & 80.4 & 377 & 56.4 & \\
\hline Ethnicity & & & & & & & $<0.001$ \\
\hline Saxwe & 939 & 76.7 & 479 & 82.6 & 479 & 71.7 & \\
\hline Others & 286 & 23.3 & 97 & 17.4 & 189 & 28.3 & \\
\hline Marital status & & & & & & & 0.304 \\
\hline Alone & 230 & 18.8 & 112 & 20.1 & 118 & 17.7 & \\
\hline Not Alone & 995 & 81.2 & 445 & 79.9 & 550 & 82.3 & \\
\hline Caregivers' occupation & & & & & & & 0.016 \\
\hline household tasks only & 35 & 2.9 & 23 & 4.1 & 12 & 1.8 & \\
\hline Household + Income generating activities & 1190 & 97.1 & 534 & 95.9 & 656 & 98.2 & \\
\hline Type of caregivers' occupation & & & & & & & \\
\hline Agricultural activities & 691 & 56.4 & 413 & 74.1 & 278 & 41.6 & $<0.001$ \\
\hline Food process/Post-harvesting & 285 & 23.3 & 151 & 27.1 & 134 & 20.1 & 0.004 \\
\hline Small trade & 514 & 42 & 211 & 37.9 & 303 & 45.4 & 0.009 \\
\hline Others activities & 169 & 13.8 & 40 & 7.2 & 129 & 19.3 & $<0.001$ \\
\hline Characteristics of $\mathrm{HH}$ & & & & & & & \\
\hline Sex of HH head & & & & & & & 0.005 \\
\hline Male & 1152 & 94 & 512 & 91.9 & 640 & 95.8 & \\
\hline Female & 73 & 6 & 45 & 8.1 & 28 & 4.2 & \\
\hline Size of HH Mean $\pm S D$ & $5.31 \pm$ & .91 & 5.53 & 1.98 & 5.13 & 1.83 & $<0.001$ \\
\hline DFGP score (Means \pm SD) & $1.71 \pm$ & .282 & 2.26 & 1.231 & 1.25 & 1.137 & $<0.001$ \\
\hline Minimum DFGP $(\%)$ & & & & & & & $<0.001$ \\
\hline Yes & 126 & 10.3 & 95 & 17.1 & 31 & 4.7 & \\
\hline No & 1095 & 89.7 & 460 & 82.9 & 635 & 95.3 & \\
\hline Food security (HFIAS) & & & & & & & 0.003 \\
\hline Food secure & 242 & 19.8 & 128 & 23 & 114 & 17.1 & \\
\hline Mildly food insecure & 98 & 8 & 46 & 8.3 & 52 & 7.8 & \\
\hline Moderately food insecure & 289 & 23.6 & 107 & 19.2 & 182 & 27.2 & \\
\hline Severely food insecure & 596 & 48.7 & 276 & 49.6 & 320 & 47.9 & \\
\hline
\end{tabular}


Table 1 (continued)

\begin{tabular}{|c|c|c|c|c|c|c|c|}
\hline \multirow[t]{3}{*}{ Characteristics } & \multirow{2}{*}{\multicolumn{2}{|c|}{ All }} & \multicolumn{4}{|c|}{ Communes } & \multirow[t]{3}{*}{$p$-value } \\
\hline & & & \multicolumn{2}{|c|}{ Bopa } & \multicolumn{2}{|c|}{ Houeyogbe } & \\
\hline & $\mathrm{n}$ & $\%$ & $\mathrm{n}$ & $\%$ & $\mathrm{n}$ & $\%$ & \\
\hline Share of the HH income allocated to food & & & & & & & 0.518 \\
\hline Normal $(\leq 50 \%)$ & 866 & 70.7 & 386 & 69.3 & 480 & 71.9 & \\
\hline Moderately high (50-75\%) & 324 & 26.4 & 156 & 28 & 168 & 25.1 & \\
\hline $\operatorname{High}(>70 \%)$ & 35 & 2.9 & 15 & 2.7 & 20 & 3 & \\
\hline Socioeconomic status (Wealth index) categories & & & & & & & $<0.001$ \\
\hline Poorest & 248 & 20.2 & 224 & 40.2 & 24 & 36.0 & \\
\hline Second & 240 & 19.6 & 164 & 29.4 & 76 & 11.4 & \\
\hline Middle & 244 & 19.9 & 82 & 14.7 & 162 & 24.3 & \\
\hline Fourth & 243 & 19.8 & 52 & 9.3 & 191 & 28.6 & \\
\hline Richest & 244 & 19.9 & 33 & 5.9 & 211 & 31.6 & \\
\hline
\end{tabular}

DFGP: Diversity of food groups produced; HH: Household; HFIAS: Household Food Insecurity Access Scale

revealed the complexity of determinants of infant and young child (IYC) complementary feeding practices.

Minimum dietary diversity (MDD) reflects the quality of foods given to children (Joseph et al., 2011). Positive association between MDD and age shows the poor quality of diet among the youngest children (6 to11 months) who received fewer different types of foods than older children (Table 2). This is not surprising, since semi-solid and solid foods are introduced gradually and stomach capacity at 6 months is relatively limited. This also confirms the overall tendency observed in complementary feeding practices in Benin and the West African region and was consistent with recent findings from the study on determinants of complementary feeding practices among children aged 6-23 months in seven francophone West African countries (Issaka et al., 2015b). The same trend has been reported in Ethiopia (Melkam et al., 2013). This finding could, furthermore, be explained by the quality of complementary foods introduced. Cereal porridges were recognized as the most common and first complementary foods given to children followed by family dishes. Victor et al. (2014) showed that the traditional porridges, as complementary foods in West Africa, generally provided low nutritional value due to less food diversity. Hence, it is important to place emphasis on upgrading the quality of porridges, especially for the youngest age bracket (6-11 months) of children by providing appropriate nutrition messages, including handson recipes for improved porridges, and promoting food diversification.

Likewise, the association between MDD and age is not linear and may be mediated by other factors as shown by the positive association between MDD and the interaction term DFGP x children's age (Table 3). In other words, the more production diversity at household level increases, the more children meet the requirements for MDD throughout all age groups. Thus, agricultural diversity was strongly associated with improving quality of complementary foods. Following
Table 2 Types of food given to children aged 6-23 months and dietary diversity score by age group, Southern Benin $(n=1225)$

\begin{tabular}{|c|c|c|c|c|c|c|c|c|}
\hline \multirow[t]{3}{*}{ Food group } & \multicolumn{8}{|c|}{ Age of children (months) } \\
\hline & \multicolumn{2}{|c|}{$6-11$} & \multicolumn{2}{|c|}{$12-17$} & \multicolumn{2}{|c|}{$18-23$} & \multicolumn{2}{|l|}{$6-23$} \\
\hline & $\mathrm{n}$ & $\%$ & $\mathrm{n}$ & $\%$ & $\mathrm{n}$ & $\%$ & $\mathrm{n}$ & $\%$ \\
\hline Cereals, roots and tubers & 456 & 99.1 & 398 & 99 & 361 & 99.4 & 1215 & 99.2 \\
\hline Legumes and nuts & 189 & 41.1 & 215 & 53.5 & 212 & 58.4 & 616 & 50.3 \\
\hline Dairy products & 14 & 3 & 10 & 2.5 & 9 & 2.5 & 33 & 2.7 \\
\hline Flesh foods & 273 & 59.3 & 330 & 82.1 & 326 & 89.8 & 929 & 75.8 \\
\hline Eggs & 13 & 2.8 & 4 & 1 & 9 & 2.5 & 26 & 2.1 \\
\hline Vitamin A-rich fruits and vegetables & 176 & 38.3 & 224 & 55.7 & 228 & 62.8 & 628 & 51.3 \\
\hline Others fruits and legumes & 243 & 52.8 & 324 & 80.6 & 307 & 84.6 & 874 & 71.3 \\
\hline Dietary diversity score (mean $\pm \mathrm{SD}$ ) & \multicolumn{2}{|c|}{$2.97 \pm 1.43$} & \multicolumn{2}{|c|}{$3.74 \pm 1.21$} & \multicolumn{2}{|c|}{$4 \pm 1.07$} & \multicolumn{2}{|c|}{$3.53 \pm 1.34$} \\
\hline Total number of children & \multicolumn{2}{|l|}{460} & \multicolumn{2}{|l|}{402} & \multicolumn{2}{|l|}{363} & \multicolumn{2}{|l|}{1225} \\
\hline
\end{tabular}


Fig. 1 Prevalence of children meeting minimum dietary diversity, minimum meal frequency and minimum acceptable diet by age group for each commune a- Bopa and bHoueyogbe. $* p<0.05$;

$* * * p<0.001 ; n s$, not significant
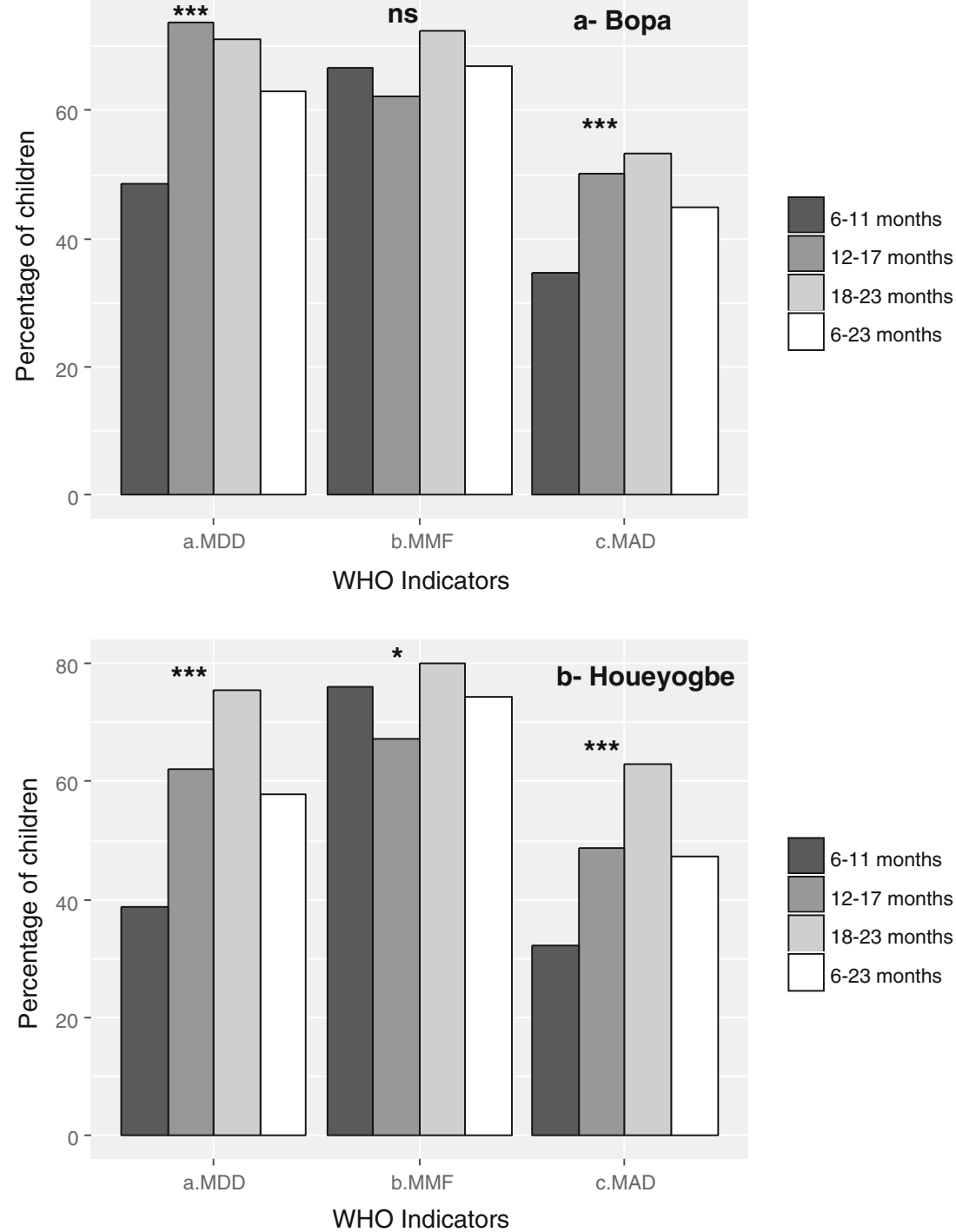

the recent PNAS publications (Berti 2015; Sibhatu et al. 2015) and to obtain a nutrition-relevant indicator, diversification was defined as the production of different food groups in farming systems (including home gardens). These findings show the link between agricultural diversification and feeding practices, especially dietary diversity. Strengthening the link between agriculture and dietary diversity can be proposed as one of the solutions to improve infant and young child nutrition. A study conducted in Benin by Segnon and Achigan-Dako (2014) showed that achieving food security can be fostered through production and consumption policies that include the valorization of wild edible plants.

The interaction term 'share of income allocated to feeding $\mathrm{x}$ 'households' residence' was strongly associated with MDD. This means that, in this study, the trend of MDD varied from one commune to another and according to the share of income allocated to feeding. The higher the share of income spent on food, the less probable MDD will be met in Houeyogbe. In contrast, whatever the share of income allocated to food, the probability of meeting MDD remains more or less the same in Bopa. This can be explained by the fact that Bopa is a purely rural area with high local biodiversity and consumption of own produced foods while the villages in Houeyogbe are closer to the main road and more dependent on food purchases. Furthermore, in the same poverty conditions, the "Saxwe" living in Bopa have fewer difficulties accessing local dietary resources compared to those living in Houeyogbe. The cost of food access is higher in Houeyogbe than Bopa. Achigan-Dako et al. (2011) found that the use of a species as a vegetable depended on sociocultural attributes in addition to geographical occurrence.

Bopa provided a better diversity of food groups produced on-farm than Houeyogbe (Table 1). It is generally known that the higher share of income a household spends on food, the more likely the household is poor (Deaton, 2003). So, poor households bought probably only cereals/tubers and better-off households meat, fruits and vegetables. This result could 
Table 3 Factors associated with minimum dietary diversity of 6-23 months children in Southwest of Benin, based on multilevel logistic regression, $n=1225$

\begin{tabular}{|c|c|c|c|c|c|}
\hline \multirow[t]{2}{*}{ Variables } & \multicolumn{2}{|l|}{ Logit } & \multicolumn{2}{|c|}{ Odd-Ratio } & \multirow[t]{2}{*}{$p$-value } \\
\hline & Estimate & $95 \% \mathrm{IC}$ & Estimate & $95 \% \mathrm{IC}$ & \\
\hline Intercept & 0.31 & $-0.15 ; 0.76$ & 1.36 & $0.86 ; 2.15$ & \\
\hline DFGP & 0.16 & $0.05 ; 0.27$ & 1.17 & $1.05 ; 1.31$ & \\
\hline \multicolumn{6}{|l|}{ Children age } \\
\hline Linear & 0.97 & $0.60 ; 1.33$ & 2.63 & $1.82 ; 3.78$ & \\
\hline Quadratic & 0.08 & $-0.27 ; 0.42$ & 1.08 & $0.76 ; 1.53$ & \\
\hline \multicolumn{6}{|l|}{ Share of income allocated to feeding } \\
\hline Linear & 0.22 & $-0.57 ; 1.01$ & 1.25 & $0.57 ; 2.76$ & \\
\hline Quadratic & -0.37 & $-0.90 ; 0.17$ & 0.69 & $0.41 ; 1.18$ & \\
\hline \multicolumn{6}{|l|}{ Commune } \\
\hline Bopa & Ref & & & & \\
\hline Houeyogbe & -0.67 & $-1.23 ;-0.11$ & 0.51 & $0.29 ; 0.90$ & \\
\hline \multicolumn{6}{|l|}{ Ethnicity } \\
\hline Sahoue & Ref & & & & \\
\hline Others & -0.46 & $-0.95 ; 0.02$ & 0.63 & $0.39 ; 1.02$ & \\
\hline DFGP $\times$ Children age & & & & & 0.0294 \\
\hline$D F G P \times($ Children age $=$ Linear $)$ & -0.02 & $-0.19 ; 0.16$ & 0.98 & $0.83 ; 1.17$ & \\
\hline$D F G P \times($ Children age $=$ quadratic $)$ & -0.23 & $-0.40 ;-0.06$ & 0.79 & $0.67 ; 0.94$ & \\
\hline Share of income allocated to feeding $\times$ Commune & & & & & 0.0083 \\
\hline$($ Share of income allocated to feeding $=$ Linear $) \times($ Commune $=$ Houeyogbe $)$ & 0.55 & $-0.50 ; 1.61$ & 1.74 & $0.61 ; 4.98$ & \\
\hline (Share of income allocated to feeding $=$ Quadratic $) \times($ Commune $=$ Houeyogbe $)$ & 0.39 & $-0.33 ; 1.11$ & 1.47 & $0.72 ; 3.02$ & \\
\hline Commune $\times$ Ethnicity & & & & & 0.0009 \\
\hline$($ Commune $=$ Houeyogbe $) \times($ Ethnicity $=$ Others $)$ & 1.05 & $0.43 ; 1.66$ & 2.85 & $1.54 ; 5.27$ & \\
\hline
\end{tabular}

DFGP: Diversity of food group produced

Ref: Reference category

$P$-values are those with likelihood-ratio test

No p-value was computed for terms that are part of higher-order interaction

explain how the purchasing power or market integration could affect the dietary diversity in Houeyogbe but less so in Bopa. Hence, the probability of meeting MDD in Houeyogbe decreased among children from households with moderate or high shares of income allocated to food. So, in the area under higher urban influence, increasing share of income allocated to feeding constitutes a risk factor negatively influencing dietary diversity. This finding corroborates a recent study where urban location was significantly associated with inadequate dietary diversity among mothers in Benin (Issaka et al., 2015b). While in rural areas households can compensate for potential dietary deficiency by diversifying their own food production, diets of people living in urban areas are likely to be more affected by higher poverty rates.

Supplementation, fortification and dietary diversification are the potential approaches that decision makers should explore for improving nutrition, taking into account context, urgency and resource availability. Besides vitamin A supplementation integrated into the immunization campaigns by the ministry of health and salt iodization under the responsibility of the Ministry of Agriculture, the Benin Government stresses the importance of food and nutrition security in the national strategy of the agricultural sector (Benin, 2017). Despite several initiatives, movements and commitments at global level, such as the Sustainable Development Goals (SDG), the Scaling Up Nutrition movement (SUN), the Global Alliance for Improved Nutrition (GAIN), Renewed Efforts Against Child Hunger and Nutrition (REACH), the new G8 Food Security and Nutrition Alliance and Zero Hunger Challenge, working on reduction of food insecurity and malnutrition, including micronutrient deficiencies, so far progress is still insufficient, especially in sub-Saharan Africa. Hence the need to consider the socio-economic determinants that explain the lack of progress in each country in order to better contextualize the interventions. Direct addition of micronutrient supplements like sprinkles, baobab and moringa powders (Houndji et al., 2013) to home-prepared complementary foods is gaining ground as a sustainable strategy for improving the micronutrient quality of children's diets (Adu-Afarwuah et al., 2007). Our study shows that nutrition-sensitive 
Table 4 Factors associated with minimum meal frequency of $6-$ 23 months old children in Southern Benin, based on multilevel logistic regression, $n=1225$

\begin{tabular}{|c|c|c|c|c|c|}
\hline & Logits & & Odd ratio & & \\
\hline & Estimates & $95 \% \mathrm{CI}$ & Estimates & $95 \% \mathrm{CI}$ & $p$-value \\
\hline Intercept & 2.66 & $1.31-4.01$ & 14.30 & $3.69-55.33$ & $<0.0001$ \\
\hline Ethnicity & & & & & 0.0214 \\
\hline Saxwe & Ref & & & & \\
\hline Others & 0.56 & $0.12-1.00$ & 1.75 & $1.13-2.72$ & \\
\hline \multicolumn{6}{|l|}{ Marital status } \\
\hline Single & Ref & & & & \\
\hline Married & -1.36 & $-2.39-0.33$ & 0.26 & $0.09-0.72$ & \\
\hline Caregiver's occupation & & & & & 0.0326 \\
\hline Householdkeeping & Ref & & & & \\
\hline Others & -0.97 & $-1.97-0.03$ & 0.38 & $0.14-1.03$ & \\
\hline HH size & -0.18 & $-0.34--0.03$ & 0.83 & $0.71-0.97$ & $<0.0001$ \\
\hline Marital status $\times$ HH size & & & & & 0.0055 \\
\hline$($ Status $=$ Married $) \times H H$ size & 0.25 & $0.07-0.42$ & 1.28 & $1.07-1.53$ & \\
\hline
\end{tabular}

HH: Household

Ref: Reference category

$P$-values are those with likelihood-ratio test agricultural diversification (including home gardens), appears to be an endogenous solution. Simultaneously, strategies such as Integrated Management of Childhood Illnesses (IMCI management of immunization, deworming, management of diarrheal and infectious diseases, vitamin A supplementation, iron and folic acid), should be strengthened in the health pyramid. Health and food and nutrition security interventions should also be coupled with WASH (Water Sanitation and Hygiene). Moreover, education and awareness raising of appropriate feeding practices and behavior change communication through counseling and culinary demonstration should be implemented in order to improve child well-being.

Another important factor affecting the probability of reaching MDD was the combined effect of the ethnicity of household heads and the commune of residence. Among "Saxwe" households, children living in Bopa had higher probability of meeting MDD than those living in Houeyogbe. In contrast, among minority ethnic groups, children living in Houeyogbe had higher probability of meeting MDD than those living in Bopa. As the native ethnic group, "Saxwe" are used to consuming a diversity of local food resources that are more readily available in Bopa than in Houeyogbe, these local food resources are part of their food habits. Avohou et al. (2012) found that ethnicity affected the composition of species managed at the community level. Moreover, children from minority ethnic groups had higher probability of meeting MDD in Houeyogbe than in Bopa owing to the purchase of foods close to their cultural food habits. This finding could confirm that the interplay of socio-cultural attributes and agroecological conditions could explain the diversity of food plants selected and used by communities (Segnon \& Achigan-Dako, 2014).
Regarding the minimum meal frequency (MMF), gender aspects and household size were identified as associated factors to complementary feeding practices. Child feeding was influenced by the primary caregivers' occupation. Caregivers' occupations could be one of the main factors affecting complementary feeding practices, especially the frequency of meals needed (MMF) to cover a child's nutrient requirements. This has also been observed by Maisonneuve et al. (2014) who pointed out the dynamic between women's daily activities and household food security with potential impact on child feeding practices.

The interaction term household size $\mathrm{x}$ marital status of mothers or primary caregivers had a strong association with adequate MMF. We observed that children were more vulnerable to suboptimal meal frequency when they lived in large female-headed households. On the contrary, household size did not significantly influence probability of meeting MMF in male-headed households. This finding shows the important role of fathers in food security at household level on the one hand and the limited access of women to material and immaterial resources such as land, innovations and knowledge, in the Beninese socio-cultural context on the other hand. As demonstrated in a recent study focused on household food availability in Sub-Saharan Africa, crop production was the major source of energy, contributing $60 \%$ of food availability (Frelat et al., 2016). Consequently, it may be difficult for women in rural areas to ensure food security as household head where land is a limiting factor for them. Women's economic empowerment constitutes one of the Sustainable Development Goals (SDGs), the implementation of which would significantly contribute to reducing mothers' vulnerability and thus contribute to better wellbeing of children. 


\subsection{Limitations of study}

The study was carried out in Southern Benin during a period of average food availability. Therefore, the results are not automatically applicable to other seasons or other geographical/ agro-ecological areas in the country. We recommend a similar study during the lean period in order to document the determinants of child feeding practices across seasons and to better orient decisions of policy makers related to appropriate strategies for child well-being. Since, the study has been carried out only in Southern Benin, the results should not be generalized for the whole country.

\section{Conclusion}

The study revealed different factors associated with selected WHO recommended complementary feeding practice indicators. The factors included: child age, household production diversity, share of the household income allocated to food, commune of residence, ethnic group of household head, caregivers' occupation, marital status of caregivers and household size. The results, furthermore, revealed interactions between some of these factors showing the interdependence or complementarity of factors in determining feeding practice behaviors. Providing quantity and quality of diet to meet infants' requirements implies enhancing households' food security related to diversification of the farming system. Socio-cultural characteristics determining food habits influenced the choice of local resources used for food within certain environments. Furthermore, gender aspects and household size influence the achievement of minimum meal frequency. Achieving appropriate complementary feeding practices will require multisectoral interventions encompassing agriculture, nutrition and social affairs. Emphasis on appropriate nutrition messaging linked to the promotion of food group diversification in farming-systems including home gardens or nutritionsensitive agriculture appear to be important in improving quality of complementary feeding practices. Reducing women's workload through improved working conditions should decrease the burden on their time availability and create more time for child care. Targeting women, mainly single-women, as vulnerable groups, through specific interventions focused on improving access and control over resources could improve complementary feeding practices.

\footnotetext{
Acknowledgements The authors sincerely thank the contribution of all respondents in the study areas for the time spent attending to the surveys and sharing their knowledge about complementary feeding practices. They acknowledge the contribution of: the mayors of the two communes, chiefs of the study villages and Mr. Adolphe Metahou from ESAM, a local NGO, for mobilizing and facilitating field activities and thank the whole team of fieldworkers.
}

Funding The present study was carried out within the FoodAfrica project "Enhancing food and nutrition security in Sub-Saharan Africa". Work package 4 of the FoodAfrica Project was implemented by Bioversity International in Southern Benin from 2012 to 2018 and funded by the Finnish Ministry of Foreign Affairs and the CGIAR research program, Agriculture for Nutrition and Health (A4NH).

\section{Compliance with ethical standards}

Conflicts of interest The authors declare that they have no conflicts of interest. The article is original work and has not been submitted for publication elsewhere.

Ethical clearance was obtained from Benin National Ethics Committee for Scientific Research. Political authorities of the two communes were informed and approved the study. Written informed consent of the enrolled children's parents was obtained after they received complete information about the study in the local language. All children that were severely malnourished (wasted) during the survey were referred to the nearest malnutrition management center.

Open Access This article is distributed under the terms of the Creative Commons Attribution 4.0 International License (http:// creativecommons.org/licenses/by/4.0/), which permits unrestricted use, distribution, and reproduction in any medium, provided you give appropriate credit to the original author(s) and the source, provide a link to the Creative Commons license, and indicate if changes were made.

\section{References}

Achigan-Dako, E. G., N'Danikou, S., Assogba-Komlan, F., AmbroseOji, B., Ahanchede, A., \& Pasquini, M. W. (2011). Diversity, geographical, and consumption patterns of traditional vegetables in sociolinguistic communities in Benin: Implications for domestication and utilization1. Economic Botany, 65(2), 129.

Adu-Afarwuah, S., Lartey, A., Brown, K. H., Zlotkin, S., Briend, A., \& Dewey, K. G. (2007). Randomized comparison of 3 types of micronutrient supplements for home fortification of complementary foods in Ghana: Effects on growth and motor development. The American Journal of Clinical Nutrition, 86(2), 412-420.

Agueh, V. D., Makoutode, M., Diallo, P., Soton, A., \& Ouendo, E. M. (1999). Infant malnutrition and associated maternal factors in a secondary city south of Benin, Ouidah. Revue d'Épidémiologie et de Santé Publique, 47(3), 219-228.

Avohou, H. T., Vodouhe, R. S., Dansi, A., Kpeki, B., \& Bellon, M. (2012). Ethnobotanical factors influencing the use and management of wild edible plants in agricultural environments in benin. Ethnobotany Research and Applications, 10, 571-592.

Bellon, M. R., Ntandou-Bouzitou, G. D., \& Caracciolo, F. (2016). Onfarm diversity and market participation are positively associated with dietary diversity of rural mothers in southern Benin, West Africa. PloS One, 11(9). https://doi.org/10.1371/journal.pone. 0162535 .

Benin, R. (2017). Paln stratégique de développement du secteur agricole (PSDSA): Orientations stratégiques 2025 et Plan national d'investissements agricoles et de sécurité alimentaire et nutritionnelle (PNIASAN) 2017-2021. Ministère de l'Agriculture, de l'Elevage et de la Pêche.

Benin Consulting, G. (2011). Plan de développement communal Commune de Houéyogbé.

Berti, P. R. (2015). Relationship between production diversity and dietary diversity depends on how number of foods is counted (letter). Proceedings of the National Academy of Sciences, 112(42), 5656. 
Bilinsky, P., \& Swindale, A. (2010). Months of Adequate Household Food Provising (MAHFP) for Measurement of Household Food Acess: Indicator guide (Vol. 4). Washington, D.C.: FHI 360/ FANTA.

Black, R. E., Victora, C. G., Walker, S. P., Bhutta, Z. A., Christian, P., De Onis, M., et al. (2013). Maternal and child undernutrition and overweight in low-income and middle-income countries. The Lancet, 382(9890), 427-451.

Brown, K., Henretty, N., Chary, A., Webb, M. F., Wehr, H., Moore, J., et al. (2014). Mixed-methods study identifies key strategies for improving infant and young child feeding practices in a highly stunted rural indegenous population in Guatemala. Maternal and Child Nutrition. https://doi.org/10.1111/mcn.12141.

Chapagain, R. (2013). Factors affecting complementary feeding practices of Nepali mothers for 6 months to 24 months children. Journal of Nepal Health Research Council, 11(24), 205-207.

Coates, J., Swindale, A., \& Bilinsky, P. (2007). Household food insecurity Acess scale (HFIAS) for measurement of food access: Indicator guide (version 3). Washington, D.C.: Food And Nutrition Technical Assistance Project, Academy for Educational Development.

Crawley, M. J. (2013). The R Book The Atrium Southern Gate, Chichester, West Sussex, United Kidom. .

Deaton, A. (2003). Household surveys, consumption, and the measurement of poverty. Economic Systems Research, 15(2), 135-159.

Fein, S. B., Labiner-Wolfe, J., Scanlon, K. S., \& Grummer-Strwan, L. M. (2008). Selected complementary feeding practices and their association with maternal education. Pediatrics, 122, S91-S97. https://doi. org/10.1542/peds.2008-13151.

Filmer, D., \& Pritchett, L. H. (2001). Estimating wealth effect without expenditure data or tears: An application to educational enrollments in state of India. Demography, 38, 115-132.

Frelat, R., Lopez-Ridaura, S., Giller, K. E., Herrero, M., Douxchamps, S., Djurfeldt, A. A., et al. (2016). Drivers of household food availabilty in sub-Saharan Africa based on big data from small farms. Proceedings of the National Academy of Sciences, 113(2), 458-463.

Gibson, R., \& Ferguson, E. (2008). An interactive 24-hour recall for assessing the adequacy of iron and zinc intakes in developing countries. HarvestPlus Technical Monograph 8. Washingtion, DC and Cali: International Food Policy Research Institute (IFPRI) and International Center for Tropical Agriculture (CIAT).

Houndji, S., Bodjrenou, S. F., Londji, S. B., Ouetchehou, R., Acakpo, A., Amouzou, K. S., et al. (2013). Amélioration de l'état nutritionnel des enfants âgés de 6 à 30 mois à Lissèzoun (Centre-Bénin) par la poudre de feuilles de Moringa Oleifera. International Journal of Biological and Chemical Sciences, 7(1), 225-235.

INSAE-Benin (2006). Enquête Démographique et de santé(EDSB-III) Bénin, 2006.

INSAE-Benin (2013). Résultats provisoires du RGPH 4.

INSAE-Benin (2014). Analyse Globale de la Vulnérabilité et de la Sécurité Alimentaire (AGVSA) - République du Bénin. Programme Alimentaire Mondiale.

Issaka, A. I., Agho, K. E., Burns, P., Andrew, P., \& Dibley, M. J. (2014). Determinants of inadequate complementary feeding practices among children aged 6-23 months in Ghana. Public Health Nutrition, 18(4), 669-678.

Issaka, A. I., Agho, K. E., Page, A. N., Burns, P. L., Stevens, G. J., \& Dibley, M. J. (2015a). Determinants of suboptimal complementary feeding practices among children aged 6-23 months in four anglophone west African countries. Maternal \& Child Nutrition, 11(Suppl 1), 14-30.

Issaka, A. I., Agho, K. E., Page, A. N., Burns, P. L., Stevens, G. J., \& Dibley, M. J. (2015b). Determinants of suboptimal complementary feeding practices among children aged 6-23 months in seven francophone west African countries. Maternal \& Child Nutrition, 11(1), 31-52. https://doi.org/10.1111/mcn.12193.

Issaka, A. I., Agho, K. E., Page, A. N., Burns, P. L., Stevens, G. J., \& Dibley, M. J. (2015c). The problem of suboptimal complementary feeding practices in West Africa: What is the way forward? Maternal \& Child Nutrition, 11(1), 53-60. https://doi.org/10.1111/ men.12195.

Joseph, C., Ownby, D., Havstad, S., Woodcroft, K., Wegienka, G., Mackechnie, H., et al. (2011). Early complementary feeding and risk of food sensitization in a birth cohort. Journal of Allergy and Clinical Immunology, 127, 1203-1201.

Khanal, V., Sauer, K., \& Zhao, Y. (2013). Determinants of complementary feeding practices among Nepalese children aged 6-23 months: Findings from demographic and health survey 2011. BMC Pediatrics, 13(131). https://doi.org/10.1186/1471-2431-13-131.

Lutter, C. K., Daelmans, B. M. E. G., de Onis, M., Kothari, M. T., Ruel, M. T., Arimond, M., et al. (2011). Undernutrition, poor feeding practices, and low coverage of key nutrition interventions. Pediatrics, 128(6), 1418-1427.

Magnani, R. (1997). Sampling guide. http://micronutrient.org/ nutritiontoolkit/ModuleFolders/5.Sampling/resources/FANTA Sampling_Guide.pdf, Accessed 18 November 2016.

Maisonneuve, C., Sanou, D., Ouattara, K., Nana, C., Yaya, S., Blanchet, R., et al. (2014). Women's empowerment: A key mediating factor between cotton cropping and food insecurity in western Burkina Faso. Journal of Food Security, 2(2), 51-58.

Melkam, A., Molla, M., Zelalem, B., \& Azeb, A. (2013). Dietary diversity and meal frequency practices among infant and young children aged 6-23 months in Ethiopia: A secondary analysis of Ethiopian demographic and health survey. Journal Nutrition and Metabolism. https://doi.org/10.1155/2013/782931.

Menon, P. (2012). The crisis of poor complementary feeding in South Asia: Where next? Maternal \& Child Nutrition, 8(1), 1-4.

Ogbo, F. A., Page, A., Idoko, J., Fernanda, C., \& Agho, K. E. (2015). Trends in complementary feeding indicators in Nigeria, 2003-2013. BMJ Open, 5, e008467. https://doi.org/10.1136/bmjopen.

Rutstein, S. O., \& Kiersten, J. (2004). The DHS wealth index. DHS comparative. (Vol. 6). Calverton, Maryland: ORC Macro.

Sarl, I. A. (2010). Plan de développement communal (2011-2015)Commune de Bopa.

Schreiner, M. (2012). A simple poverty scorecard for Benin. http://www. microfinance.com/English/Papers/Scoring_Poverty_Benin_EN_ 2010.pdf, Accessed 03 Octobre 2015

Segnon, A. C., \& Achigan-Dako, E. G. (2014). Comparative analysis of diversity and utilization of edible plants in arid and semi-arid areas in Benin. Journal of Ethnobiology and Ethnomedicine, 10, 80-100.

Sibhatu, K., Krishna, W., \& Qaim, M. (2015). Reply to Berti: Relationship between production and consumption diversity remains small also with modified diversity measures. Proceedings of the National Academy of Sciences, 112(42), 5657.

Team, R. D. C. (2015). R: A language and environment for statistical computing. R Foundation for Statistical Compunting. http://www. R-project.org, Accessed 1 April 2015.

UNICEF. (2011). Programming guide: Infant and young child feeding. New York: UNICEF.

Upul, S., Sanjeeva, S. P. G., Hiranya, J., Indika, S., \& Michael, J. D. (2012). Determinants of inappropriate complementary feeding practices in young children in Sri Lanka: Secondary data analysis of demographic and health survey 2006-2007. Maternal \& Child Nutrition, 8(1), 60-77.

Victor, R., Baines, S., Agho, K. E., \& Dibley, M. J. (2014). Factors associated with inappropriate complementary feeding practices among children aged 6-23 months in Tanzania. Maternal \& Child Nutrition, 10, 545-561.

Vyas, S., \& Kumaranayake, L. (2006). Constructing socio-economics status indices: How to use principal components analysis. doi: https://doi.org/10.1093/heapol/czl029.

WHO. (2003). Global strategy for infant and young child feeding. Geneva: World Health Organization. 
WHO (2008). Indicators for assessing infant and young children feeding practices. Part I. Definitions. Geneva: World Health Organization.

WHO. (2010). Indicator for assessing infant and young child feeding practices- part III: Country profiles. Geneva: World Health Organization.

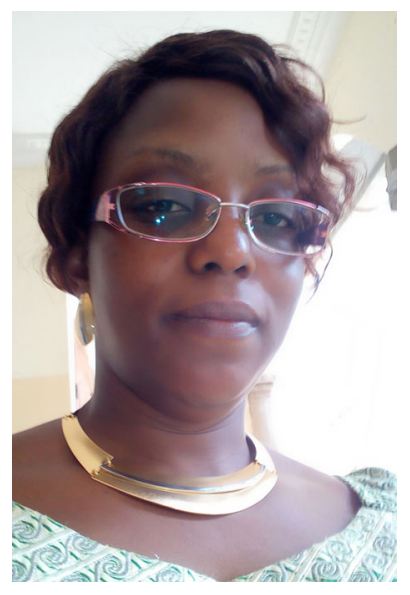

Irene Medeme Mitchodigni is an Agronomy engineer with a diploma in Nutrition and Food Science from the Faculty of Agronomy Sciences of the University of Abomey-Calavi in Benin. She holds a master's degree in Nutrition and Food Technology of the Louvain Catholic University and Gembloux University in Belgium. Since 2012, she has been working on her $\mathrm{PhD}$, which focuses on improving complementary feeding practices for the wellbeing of children. She has over 14 years of experience in global nutrition and food security interventions and has collaborated with many international organizations, government agencies and research institutions. She has participated in the elaboration of Policy papers such as The New Alliance for Food Security and Nutrition Benin Cooperation Framework.

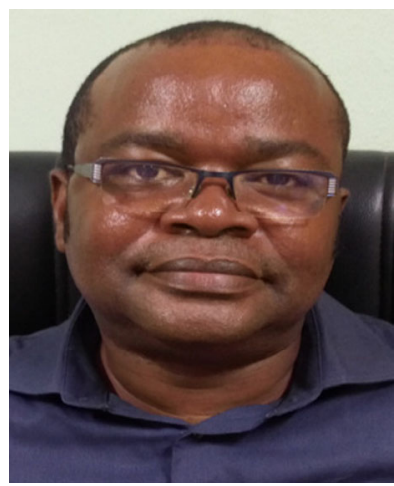

Waliou Amoussa Hounkpatin has been an Agro-nutritionist since 1993 with a PhD in Nutrition \& Health. He obtained his MSc in Public Health Nutrition at the prestigious London School of Hygiene and Tropical Medicine. He is Lecturer and Researcher in the Department of Nutrition and Food Sciences (DNSA), Faculty of Agricultural Sciences (FSA), University of Abomey-Calavi (UAC) Benin. There he is also in charge of study and academic affairs in DNSA. He has been involved in Regional and International Training in Nutrition for many years and in 2012, became the Executive Secretary of FINSA - International Training in Nutrition and Food Science which today has 25 years of experience in regional and international training in Nutrition and Food security. Dr. Amoussa has been leading FINSA as Director since 2014. In addition, his main research interests are Community nutrition, Nutrition and Food Security, the double burden of nutrition and also the use of stable isotopes to monitor nutritional outcomes and nutritional status of vulnerable groups. His recent work has included a Food Based Approach to reduce vitamin A deficiency, Evidence informed-decision making in nutrition and several research projects with Bioversity International and International Atomic Energy Agency (IAEA) such as "Contributing to the evidence base to improve stunting reduction programs".

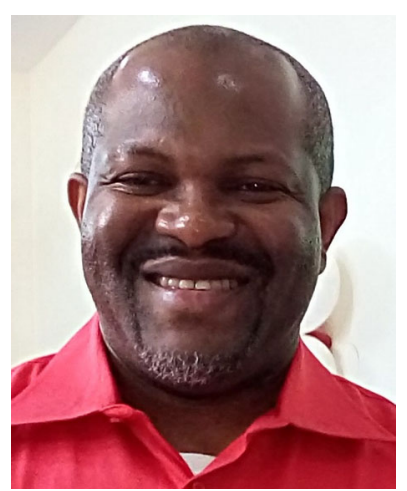

Gervais D. Ntandou-Bouzitou holds a $\mathrm{PhD}$ in International Nutrition from the University of Montreal. He has 17 years' experience in research, teaching and management of Public Health, Nutrition and Nutrition-Sensitive Agriculture projects at National and International levels. He is currently working as Nutrition and Food Security Policy Expert at the Food and Agriculture Organization of the United Nations (FAO) supporting the Government of Niger in refinement, finalization and costing of the action plan of the National Policy of Nutrition Security. Before joining FAO, he worked for six years at Bioversity International, leading research for development projects on the contribution of agricultural biodiversity to the improvement of nutrition and health of women and children.

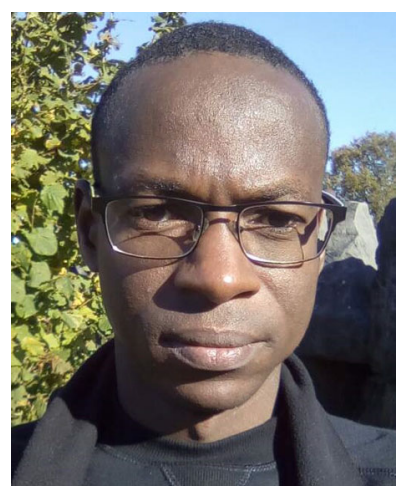

Hermane T. AVOHOU is an Agronomy engineer and holds an MSc in Biostatistics at the School of Statistics, Biostatistics and Natural Sciences of the Catholic University of Louvain (LSBA / UCL). He has developed skills in statistical control of industrial quality, in data management and natural resource management. $\mathrm{He}$ has written, several articles and some books related to management of wild edible plants in agricultural environments, agroecology and ethnobotany areas.

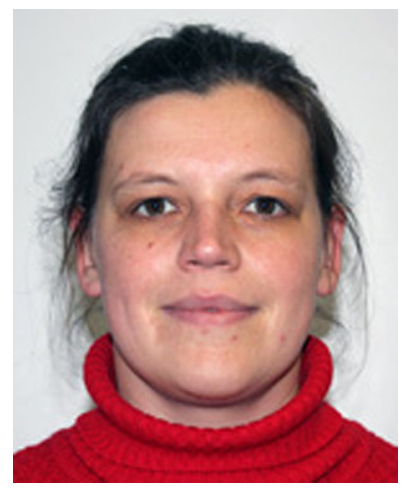

Dr. ir. Céline Termote is an Associate Scientist at Bioversity International based in Nairobi, Kenya. Dr. Termote has an MSc and $\mathrm{PhD}$ from Ghent University in Belgium. Céline started her career as development worker and has over 10 years of experience in multidisciplinary research in Sub-Saharan Africa. She is fascinated by the multiple links and complexity surrounding people and their food systems and fosters participatory action research. Her research encompasses ethnobotany, agro-ecology, culture, food security, diverse value chains, diets and nutrition. 


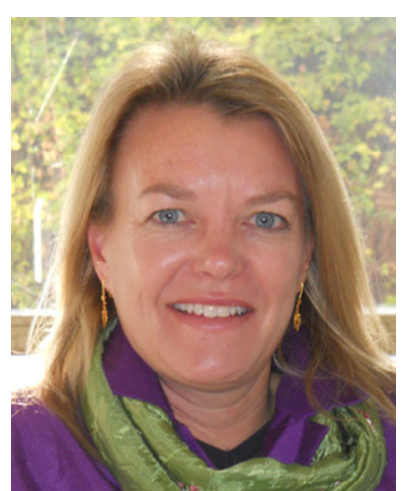

Dr. Gina Kennedy (Senior Scientist, Bioversity International). Dr. Kennedy is a Senior Scientist with Bioversity International and leader of the Healthy Diets Initiative. She is an international public health nutrition specialist. Her research interests include measurement of dietary diversity and diet quality and assessment of nutritional problems in developing countries. For the past ten years she has worked on nutrition assessment in developing countries, including assessing the contribution of agricultural biodiversity on nutrient intake. Prior to joining Bioversity, she worked for the Nutrition Division of FAO on food-based indicators for use in food and nutrition security programs, nutrition assessment and nutrient requirements. She also managed a research project studying the impact of food security interventions combined with nutrition education on use of locally available foods to improve nutrient intakes, micronutrient status and growth of young children. Prior to working for FAO, she worked for GIZ in Guinea, West Africa and the public health system in the Republic of Kiribati. She received her $\mathrm{PhD}$ in public health nutrition from Wageningen University and her Master of Public Health from the University of Alabama, Birmingham.

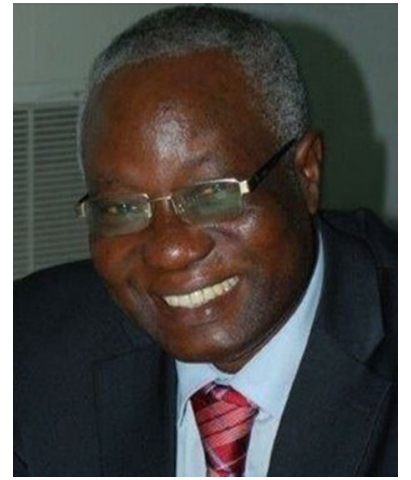

D. Joseph Hounhouigan received his $\mathrm{PhD}$ from the University of Wageningen (The Netherlands) and his Master's degree at the University of Montpellier (France) in nutrition and food science. His expertise is on characterization, optimization and product development, based on traditional food products, especially fermented cereals, roots and tubers, non-timber forest products and leguminous grains. He also has extensive management experiences, having headed several institutions such as the Nutrition and Food Sciences Department of the Faculty of Agronomic Sciences of the University of Abomey-Calavi (FSA/UAC Benin, 13 years), the Nutrition and Food Science International training (12 years), the National Direction of Scientific and Technological Research of the Ministry in charge of scientific research (3 years). He is the current Dean of the FSA/UAC and coordinates many Food and Nutrition research projects. He has published more than 180 scientific papers in international journals. 